\title{
The "Key" to Successful Transitions for Young People Leaving Residential Child Care: The Role of the Keyworker
}

\section{Stephanie Holt \& Gloria Kirwan}

To cite this article: Stephanie Holt \& Gloria Kirwan (2012) The "Key" to Successful Transitions for Young People Leaving Residential Child Care: The Role of the Keyworker, Child Care in Practice, 18:4, 371-392, DOI: 10.1080/13575279.2012.713853

To link to this article: https://doi.org/10.1080/13575279.2012.713853

曲 Published online: 11 Sep 2012.

Submit your article to this journal $\pi$

Џll Article views: 1113

Citing articles: 16 View citing articles 지 


\title{
The "Key" to Successful Transitions for Young People Leaving Residential Child Care: The Role of the Keyworker
}

\author{
Stephanie Holt \& Gloria Kirwan
}

In the absence of mandatory planning and support to assist all young people who leave care in Ireland, after-care provision is a "neglected" area of service provision and has been criticised for being inconsistent and ad hoc. The benefits of keyworker support for young people making the transition out of care is more clearly articulated within the literature and across policy statements and is firmly embedded as a model of good practice in working with young people in residential care. The study reported here sets out to conduct an in-depth exploration of the concept of keyworking. This is achieved by engaging young care-leavers, residential care providers and after-care support workers in qualitative interviews. By asking young people and care providers about their experiences of keyworking, it attempts to drill down into both the benefits and possible downsides of this practice model. The findings and discussion presented here are based on the pilot stage of this study, and although the findings can only be regarded as tentative in nature some important issues have emerged from the pilot stage as reported here.

\section{Introduction and Background}

The point of transition from residential care to after-care is a particular point of change in the life of a young person that requires the young person to negotiate through a period of significant adaptation and all the challenges that moving towards independent living can pose. Cognisant of the particular challenges that transition from care presents, calls for the development of a dedicated after-care service began over 30 years ago in Ireland with the Kennedy Report (Government Publications, 1970) and The Task Force of Child Care Services (Government Publications, 1980). These calls were reinforced by research commissioned by Focus Ireland in 2000, which confirmed a worrying correlation between early care histories and

\footnotetext{
Stephanie Holt is Assistant Professor of Social Work at Trinity College Dublin. Gloria Kirwan is Assistant Professor of Social Work at Trinity College Dublin. Correspondence to: Stephanie Holt, School of Social Work and Social Policy, University of Dublin, Trinity College, Dublin 2, Ireland. Email: sholt@tcd.ie
} 
homelessness (Kelleher, Kelleher, \& Corbett, 2000). Despite this, Gilligan (2008, p. 91), reflecting on the Irish context, describes the provision for care-leavers as "relatively neglected", with regard to the absence of a clear legislative requirement for the provision of after-care services, the ad hoc and inconsistent manner in which after-care services have developed and the lack of routine administrative data to inform general inquiry and research. Focusing specifically on the legislative basis for the provision of after-care, Section 45 of the Child Care Act 1991 stipulates that the health board "may" assist the young person for as long as the board is convinced of his/her need for assistance. This leaves open the possibility that some young people will make the transition out of care without formal assistance. Echoing Gilligan's (2008) observations, a briefing document prepared by an independent association in Ireland that works with and on behalf of children in the care system or graduates from care (EPIC, 2011) describes the provision of after-care throughout Ireland as inconsistent and ad hoc, depending more often on where young people live rather than on their individual needs. Appearing more consistently, however, is a clearly articulated role for keyworkers regarding the special support that young people require at the point in their lives when they negotiate the move out of residential care and towards post-care independence. Of specific relevance, for example, is a leaflet produced for young people leaving care, which explicitly states: "If you live in residential care, the work to prepare you for leaving care will be carried out by your key worker in your centre" (Health Service Executive, 2006, p. 1). Within the fields of policy and practice related to residential care services for young people, the recognition of "keyworking" as a core concept associated with good practice with young people across a number of different sectors is firmly embedded.

Recent reports and policy documents in Ireland refer to keyworking in positive terms, explicitly but we would argue uncritically, promoting it as intrinsically useful and supportive for the young people who receive it. For example, the value of keyworker support to service users is highlighted in the recent report commissioned by the Irish government into clerical sexual abuse, known as the Ryan Report (Government of Ireland, 2009). Action 68 (Government of Ireland, 2009, p. 49) of the Ryan Report Implementation Plan, the section that makes recommendations for improved statutory support for young people in transition out of the care system, promotes the idea that keyworking would be offered as a supportive measure to young persons in transition out of care. Key policy documents in the related areas of mental health (A Vision for Change, 2006) and homelessness (Department of the Environment, Heritage and Local Government, 2001) also include recommendations for the introduction of a system of keyworking for service users and their families.

However, exactly what is meant by keyworking by the authors of these various reports and policy documents is less clear. There is a lack of articulation within contemporary literature as to what is understood or practised in the name of keyworking and much less again available in terms of evidence-based knowledge about how it presently operates. Furthermore, the current knowledge base provides us with insufficient knowledge on how keyworking is enacted within residential childcare settings or the mechanisms by which it is enacted. 
In such a knowledge vacuum, it is possible, if not likely, that keyworking as a concept and as a practice means different things to different people. Despite the absence of a substantial body of research and debate to underpin it, keyworking is growing in recognition by policy-makers and practitioners as a positive model of service delivery. The research on which this article is based is an attempt to fill the research knowledge void that surrounds keyworking, with a specific focus on the residential childcare setting. At the time of writing, the research team has completed the pilot phase of the study, the stated aims of which are to investigate:

- what "keyworking" involves, with particular reference to its role in coordinating a focus on the needs and care plan of the young person in care;

- what "keyworking" means to young care-leavers and to residential care-workers; and

- what role, if any, the keyworking relationship plays in preparing a young person for both the transition to after care and also in the post-care period.

Heeding Gilligan's call for a "closing [of] the gap between [the] rhetoric and reality of aftercare provision" (2008, p. 98), this paper will begin with a selective review of the relevant international literature before moving on to present the findings of this pilot study on the experience of keyworking by those directly involved in it.

\section{Literature Review}

The literature review presented here addresses outcomes for young people leaving care, the importance of relationship-based practice with young people in care, the challenges of relationship-building with young people in care and the process of transitioning to after-care, assessing "readiness" for independent living, and sets out an overview of keyworking, its definitions and potential.

\section{Outcomes for young people living in residential care}

Study upon study make reference to the fact that young people in state care, and more specifically in residential childcare, are not a homogeneous group (Dixon \& Stein, 2005; Kendrick, 2008; Owusu-Bempah, 2010). Their paths into state care, the early family experiences that have resulted in their admission to care, the timing of this admission and the quality of their care experience reflect widely diverse trajectories and backgrounds (Pinkerton, 2000). However, when outcomes for young people in care are examined, a more consistent picture emerges, with research conducted over the last three decades highlighting a disturbing trend of poor educational achievement, poor physical, mental and general well-being, homelessness, criminality, unemployment, teenage parenting and poor social networks (Bilson, Price, \& Stanley, 2010; Dixon, 2008; Dumaret, Donati, \& Crost, 2011; Martin \& Jackson, 2002; McAuley \& Davis, 2009; McClung \& Gayle, 2010; McCrystal $\&$ McAloney, 2010). A number of studies have focused on the mental health status 
and needs of young people in the care system and at the point of graduation from residential care. Houston (2011) cites studies that revealed high levels of mental health problems among young people in care, including McCann, James, Wilson, and Dunn (1996), Mount, Lister, and Bennun (2004) and, in particular, Utting, Baines, Stuart, Rowland, and Vialva (1997) who reported an association between poor long-term outcomes for young people in care and problems with their mental health. A study conducted in an urban catchment area of one Child and Adolescent Mental Health Team in Ireland (McNicholas, O'Connor, Bandyopadhyay, Doyle, O'Donovan, \& Belton, 2011) found that in a population of children in out-of-home care, those in residential care were more likely to have contact with mental health services $(83 \%)$ compared with those in foster care $(47 \%)$ or relative foster care settings $(44 \%)$. They also found that the cohort placed in residential care settings were more likely to display behavioural problems and socialisation difficulties. Of particular relevance to this present paper is the consistent finding of young people in residential care faring consistently worse, not only compared with children in the general population but also when compared with the population of children in other forms of alternative care (Gaskell, 2009; Vinnerljung \& Sallnäs, 2008). Important also are the research findings that identify the factors that promote positive outcomes for children in care. While research to date highlighting the success of care-leavers is relatively scarce (Martin \& Jackson, 2002), what is known points consistently to the importance of stability, not solely related to stability of placement setting but also more significantly the importance of positive and stable relationships with professionals involved in their care, particularly their keyworking relationships (Dumaret et al., 2011; Martin \& Jackson, 2002; McLeod, 2010).

\section{Young People, Residential Care and the Importance of Relationships}

Although little is recorded in the recent literature about keyworking, the issue of relationships between young people in residential care and their caregivers has attracted considerable commentary and research. Keyworking is one form of relationship and one that is particularly associated with residential caregiving, and therefore the wider literature on relationships within residential care contexts is pertinent and useful as a starting point for understanding the particular and possibly unique qualities of the keyworking relationship. According to de Boer and Coady (2007), outcomes for service users in general (not only young people in residential care) are linked to the quality of the worker/service-user relationship. They identify characteristics of positive relationships between service providers and service users to include factors such as respect, acceptance, trust, warmth, liking, understanding and collaboration. Mallinson (1995, p. 9) further asserts that keyworking requires certain personal characteristics of the worker, including "natural warmth, empathy and genuineness in their approach to others".

Howe (1997, p. 162) highlights the significant effect that the quality of children's social relationships has on their socio-emotional development and concludes by asserting that the "poorer the quality of a child's relationship history, the less 
robust will be her psychological make-up, emotional integrity and social competence". As such, and of particular relevance to the population of young people in care, a care-leaver's capacity to engage positively in their current relationships is directly related to their past relational experiences. In a similar vein and drawing on "internal working models" theoretical frameworks, Dunn (1993, p. 117) posits that social or relational competence is an "emergent property of relationships", from which Howe (1997) concludes that past experiences of relationships influence how current ones are managed. Echoing these sentiments, Houston's $(2010,2011)$ research in Northern Ireland highlights the importance of relationship building as a medium for building resilience in young people. Similar to de Boer and Coady's (2007) discussion, Houston (2010, p. 367)found that resilience in young people in residential care was enhanced by workers "being there" for them, and where caring, nurturing relationships are developed by residential staff living through the "highs and lows" of the young people's lives. In a similar vein, Holland, Faulkner, and Perez-del-Alguila (2005, p. 29) focus on continuity as another essential characteristic of relationships for young people if they are to feel fully supported, stating that "the importance of a child's need for continuity of affectionate relationships has long been established".

Cashmore and Paxman (2006) discuss the need of the young person in care for "felt security", which they strongly link with positive outcomes for those young people when it is present. Their research illuminated the complexities of the lives of young people who are cared for out of home and how security of relationships was a fundamental plank in helping the young people they interviewed in mediating the experience of separation from their family of origin. Stability of placement was central to the notion of "felt security", but, for young people in residential care settings, just staying in the same placement was only one aspect of "felt security". Confirming the point by Holland et al. (2005) above, for the young people in Cashmore and Paxman's (2006) research, the issue of continuity also featured as an important factor alongside supportive relationships with those around them:

How well young people were faring "across the board" was strongly predicted by how secure they felt in care, their ability to stay on in the same placement beyond care and the level of social support available to them after leaving care. While stability in care by itself was important, it is clear that other aspects of felt security, continuity and social support were more significant. (Cashmore \& Paxman, 2006, p. 238)

In a different study of service-users, Jackson and Thomas (2001) found that what mattered most to service-users was "predictability" and "having their views taken into account". Therefore, although a solid evidence base exists concerning the positive aspects of relationships for young people in residential care, a wealth of empirical guidance concerning the barriers to positive relationships has also developed concurrently, as outlined in the next section.

\section{Challenges to Building Relationships with Young People in Care}

Gaskell (2009) cites a number of factors that can impact negatively on the formation, quality and endurance of positive relationships between young people in care and 
their caregivers. These include a young person's prior negative history of relationships, either experienced prior to their admission to care or in the context of other cared-for settings; the difficulties in overcoming any lack of trust that the young person feels towards adults in their life; the unsettling impact of constant moves and placement instability, too often a feature of the care histories of young people living in residential care; and, finally, the problem of staff retention and the recurring theme of high staff turnover in many residential care settings that mitigates against continuity, security and trust, all central characteristics of felt security and positive relationships between staff and young people in care.

Kroll (2010, p. 73) further reminds us of the difficulties for workers in establishing rapport with any young person in difficulty, and she describes her efforts to engage a young person (still in the care of his mother) with whom she is trying to work in order to assess his needs. She applies the analogy of the concept "relationship dance" developed by Stern (1977) to that beginning period when she is trying to convey to the young person that she is worth engaging with and that his work with her will be conducted in a safe emotional space, a "holding, containing environment" based on trust and respect. She considers the mechanics of such worker-young person relationships in the context of attachment theory and suggests that in the mix come hopes and expectations, fears, defence mechanisms and a range of other conflicting feelings and emotions. Other writers comment on the capacity of individual residential units to develop relationships with young people in their care, drawing attention specifically not only to the capacity of individual care staff, but perhaps more importantly to the emotional atmosphere in the unit, the leadership style and commitment to supporting optimum care staff practice (Andersson, 2005; Forkby \& Höjer, 2011; Hicks, 2008; Hicks, Gibbs, Weatherly, \& Byford, 2009). Finally, as early as 1990, Mallinson and Citarella (1990) identified gender as an issue relevant to matching keyworkers with individual residents.

In summary, young people in care are likely to have entered and journeyed though care against an historical backdrop of poor or broken attachments with their family of origin. The capacity of the residential unit and the young person to develop, maintain and sustain meaningful relationships can be critical, not only in the reparation of those earlier damaged relational attachments but also as a vital building block in the young person's capacity for independent living.

\section{Transition to After Care}

Stein captures not just the level of adjustment that leaving care involves for young people, but also how that transition is experienced by young care-leavers:

Young people leaving care have to cope with the challenges and responsibilities of major changes in their lives ... they have compressed and accelerated transitions to adulthood. (2002, p. 68) 
In many jurisdictions, age is the factor that currently determines when a young person finishes their "in care" career. A number of writers raise serious questions about the wisdom of using age as the deciding factor for when a young person leaves a "cared for" environment (Dixon \& Stein, 2005; Stein \& Munro, 2008). Responding to the concern that age is a crude and less than reliable indicator of a young person's readiness to "graduate" from residential care, Dixon and Stein (2005) argue instead for a more "through care" approach to preparing young people for life after care, including a more graduated transition that better reflects other young people's journey to adulthood. Mendes (2009, p. 87) suggests that maturity or levels of skill development would be more reliable and therefore more favourable measures of the readiness of young people to begin the transition to after-care settings. Arguing that while the formal definition of leaving care relates to the ending of state responsibility for young people in care, the reality in practice, however, is a major and, as Stein (2002) posits, "accelerated" experience of immediate rather than graduated transition from dependent child to independent and self-sufficient adult. When one considers, as Biehal and Wade (1996, p. 443) have, the vulnerability of young people living in residential care arising from their personal histories and family backgrounds and the extent of continuing post-care support of either a formal or informal nature available to them, the potential for "leaving care" to enhance this vulnerability is poignantly magnified.

Expressing similar concerns, Dinisman and Zeira (2011, p. 1420) argue instead for a need to estimate the care-leaver's "readiness" for independent living and the various factors that can influence that "readiness". Exploring this a little further, the authors identify two distinct types of life skills needed to become competent adults; the first they term "tangible" or concrete skills such as money management; and the second, felt or "intangible" skills such as relationship development. While, as stated earlier, these skills may be compromised by virtue of the young person's life experience, they are nonetheless essential for a successful transition from care. Continuity and stability of relationships that have developed in care but have the capacity to endure post care can continue to offer the young person the secure base from which the transition to independence can occur in a safe and supportive manner (Dixon \& Stein, 2005). In the mix of circumstances that young people in residential care encounter, the keyworker relationship can potentially offer a focus within which careful attention can be paid to the needs of the individual child throughout their cared for career and through which resources can be mobilised to help support a life trajectory from care to after-care that is enhancing rather than disempowering for the young person concerned.

\section{Keyworking and the Keyworker Role}

Mallinson (1995), in reviewing the history of keyworking with older people in residential care, traces the emergence of keyworking as a concept from the 1970s where it was viewed as a means of enabling better communication and collaboration across organisational divisions between residential and community services. He cites 
an early definition of a residential care keyworker by the Residential Care Association/British Association of Social Workers (1976, p. 2) as: "the person having full responsibility for the service user received into residential care and for decisions relating to the case" (Mallinson, 1995, p. 16). Mallinson also cites a later definition, which describes keyworking as:

a system for providing individualised social care through named persons. A keyworker is the person who has responsibility and accountability for the care of the service user and for decisions relating to their situation. (SCA Education, 1991, cited in Mallinson, 1995, p. 2)

There is clearly a distinction emerging within these definitions between the keyworker based within the residential care setting who is assigned to the young person and other professionals, such as the field social worker, who may also play a key role in terms of the overall management of the young person's circumstances. A number of writers refer to the key social work role provided to families and young people (for example, Gilligan, 2000; Thoburn, 2008) but the focus of this present study is the keyworking carried out by residential care-workers with residents.

Mallinson's (1995, p. 3) review of the literature and also his own research on keyworking in residential care services (Mallinson \& Citarella, 1990; Mallinson, 1992) illuminates the different aspects of keyworking that include coordination of the care plan for individual residents as well as meeting the needs of individual residents for "personalised relationships" within the unique environment of residential group care. In its document outlining the policies and procedures for children's residential centres, the Irish Health Service Executive defines keyworking as:

The provision of individualised care for each young person through a named member of the centre's staff team. While a keyworker is not solely responsible for the care of the young person it is their responsibility to co-ordinate and ensure that the team focus is on progressing the young person's care plan and the young person's life in the centre. (Health Service Executive, 2010, Section 2.4)

Byrne and McHugh (2005) identify the main features of keyworking, including the development of a trusting and respectful relationship with the service user aimed at bringing focus to the service user's well-being and particular needs. They highlight as primary the role the keyworker plays in helping the young person "make sense" of the experience of living in residential care settings, and they cite Clarke's (1998, p. 31) observation on the potential for keyworking to "improve personalised care, relationships, the clarity of the residential tasks".

It is also possible to identify another core component of the keyworker role, in particular the role the keyworker can play as a focal point of contact for the coordination and linkage of the various parties involved in the provision of residential care, including the residential care team's interaction with the young person and between the young person in care and their external interactions with family, school and the wider professional network. These interactive roles of coordinator and focal contact person appear consistently across the literature as strongly positive functions of keyworkers. Dant and Gearing (1990) have identified 
them as a positive contribution of keyworkers to the care of older people, and in Mullins' (2008) study of services for children with disabilities she highlights the benefits to families of having a keyworker who will act as a single point of contact and help them "navigate through the maze of agencies".

Sloper, Greco, Beecham, and Webb (2006) conducted research on the characteristics of keyworkers that were linked to better outcomes for families caring for a child with a disability. Although this is a different context to that of residential childcare, it is useful to note that in their findings parental satisfaction was strongly linked to keyworking services that provided emotional support, information, advice, advocacy, coordination of professional inputs and help in times of crisis.

Despite this apparent consistency regarding why keyworking helps, there is less literature suggesting a shared understanding of the keyworker role and how it should be enacted or interpreted. Mattison and Pistrang (2000, p. 14) studied services for people with learning disabilities and found variation between agency settings regarding keyworker roles and responsibilities. In her study, Mullins (2008) calls for clearer articulation in the job descriptions of keyworkers outlining what their role involves. Furthermore, Mullins (2008) and Sloper et al. (2006) agree that keyworkers were regarded as more effective by their clients when they received regular training and support related to their keyworker role. For this type of provision to become mainstream, it is suggested here that there must be a common, shared interpretation of what keyworking involves and what it is aiming to achieve. That is, it must first be clear what theoretical and skill base is required to carry out the role. In terms of residential childcare services, Byrne and McHugh (2005) suggest that keyworkers in such settings require clear understandings of attachment theory, developmental and social psychology, and be adept in a range of communication and relationship-based work skills. The relevance of attachment theory for people living in residential settings is echoed by Mattison and Pistrang (2000), who also highlight the fit between theories of loss and separation and the experiences of people living in residential care.

Therefore, the keyworker role is open to interpretation and may potentially overlap with the role of other key professionals involved in the young person's pathway through care, their field social worker in particular. Gilligan (2000) distinguishes between the caring role of staff involved in the out-of-home care of the young person $v i s$-à-vis the "coordinating" role of the social worker who invariably is responsible for ensuring that the complete package of care is functioning effectively, including planning, reviewing and sustaining vital relationships in the young person's life. From this angle, the coordinating of the day-to-day life and interactions of the young person, as carried out by the residential keyworker, can be seen as different, although overlapping with this wider, helicopter-view level of coordination that is typically the domain of the young person's assigned social worker. How well or otherwise the interaction and management of this overlap works out between the residential keyworker and the designated field social worker merits further study but was beyond the scope of this present study. 


\section{Methodology}

This pilot study adopted a case-study methodological design, one considered to be a particularly appropriate strategy aspiring for a rich and in-depth empirical investigation of a "particular contemporary phenomenon within its real life context using multiple sources of evidence" (Robson, 1998, p. 52). It allows for the possibility of investigating a social process in a comprehensive fashion and can grapple with the intricacies and dynamics of social interactions and social behaviour (Widmer, Hirschi, Serdult, \& Vogeli, 2008). For the purpose of this pilot study, the "case" is the experience of keyworking within a residential childcare setting from the perspective of young care-leavers, keyworkers and after-care workers. In allowing for in-depth exploration of this phenomenon, case-study research designs have the capacity to contain breadth and depth by combining methodological triangulation (more than one method employed), with data triangulation (where data are drawn from more than one source) (Robson, 2002). In this research, methodological triangulation is achieved through the employment of both focus group and individual interview data collection methods, while data triangulation is achieved through the collection of data from different stakeholders (care-leavers, residential keyworkers, after-care workers).

As a prerequisite to research activity in the institution under whose auspices this research was carried out, full ethical approval was sought from and granted by the Research Ethics Approval Committee of the School of Social Work and Social Policy, Trinity College Dublin.

\section{Accessing the Research Population/Entering the Field}

In the absence of ready access to this population, non-probability cluster sampling was employed: an approach generally used when there is no sampling frame available. Cluster sampling selects certain areas or clusters that are relevant to the research problem (Robson, 2002). In this pilot research, residential childcare units, which represent these clusters, were accessed through the National Residential Child Care Managers Forum. As such, this research strategy identified and engaged with key informants and gatekeepers who the researchers believed had specialised knowledge in the field and direct access to the potential research participants. This proved instrumental as the researchers were negotiating entry into the field (O'Leary, 2005). With permission from the Managers Forum, three residential units were approached and agreed to participate in the pilot study. These units were all located in one urban setting and included two long-term units for boys and one short-term and crisis unit for girls. The targeting involvement of gatekeepers also involved approaching the National AfterCare Workers Forum and a national organisation advocating on behalf of young people within and graduated from the Irish care system. A total of 20 keywork staff working in these three units participated in three focus group interviews. A further three after-care workers were accessed through the other two gatekeeping organisations and participated in individual interviews. Four young 
people were accessed through these gatekeeping sources and participated in one group and one individual interview.

\section{Collecting the Data}

Krueger and Casey (2009, p. 6) describe a focus group as "a carefully planned discussion designed to obtain perceptions on a defined area of interest in a permissive, non-threatening environment". Focus groups were chosen as the main method of data collection with the professionals and the care-leavers. This decision was taken in the confidence that this method would provide access to forms of data that would not be obtained easily through other methods, and also for its ability to study a large amount of interaction on a topic in a limited period of time (Morgan, 1997). With particular reference to care-leavers and their under-representation on the research agenda, the researchers believed that the focus group method would facilitate an exploration of "not only what participants think about an issue but also how they think about it and why they think the way they do" (Morgan, 1997, p. 20). Another broad source of strength lies in the comparisons that participants make among each other's experiences and opinions, providing the researcher with "a rare opportunity to collect direct evidence on how the participants themselves understand their similarities and differences. This actual observation of consensus and diversity is something that can happen quite powerfully through group interaction" (Morgan, 1997, pp. 20-21).

Conscious of the difficulties in getting whole residential care teams to participate in a group interview given the shift-work system in residential childcare, two of the three focus groups took place directly after the residential staff team meeting. As Krueger states:

Piggyback focus groups can be effective when you add them to another event, meeting, or occasion. (1994, p. 83)

The focus group interview began by establishing that the keyworker participants were fully informed of the purpose of the research, issues of consent and confidentiality were clarified and consent forms were signed. Each focus group took place over a one-and-a-half-hour period and was tape-recorded, with consent from the participants. Whole and partial transcriptions were then taken, from which themes emerged. The three individual interviews conducted with the after-care staff were conducted in a similar manner.

The preliminary steps taken in accessing the care-leaver sample involved both written and verbal communication. An information sheet for keyworkers and a separate one for care-leavers were given to the professional gatekeepers. These professionals also verbally explained the purpose of the research and other issues related to the research process to the care-leavers. The focus group and individual interview were arranged by the gatekeepers and took place in the organisations on both occasions. While initial access to the care-leavers was facilitated through the gatekeepers, responsibility still lay with the researchers to secure the informed consent of the care-leavers themselves. Issues of consent, anonymity and confidentiality were 
clarified prior to the interviews commencing. The focus groups took place over a two-hour period, with the individual interview spanning one hour. Both interview formats were digitally recorded, with consent from the participants. Whole and partial transcriptions were then taken, from which themes emerged. All of the interviews that were conducted between September and October 2011 were guided by semi-structured interview schedules.

The profile of the participating young people includes two male and two female care-leavers between the ages of 21 and 24 years of age. Their care careers spanned between three and 13 years in state care, predominantly but not exclusively within the residential care sector, involving between one residential care setting experience to multiple moves and experiences.

The data were analysed using NVivo (a qualitative research analysis package that ensures all data are visible for analysis, thus pre-empting selective interpretation). As the coding process is at the heart of qualitative analysis, the text was divided into units or themes and sub-divided again into smaller related themes or concepts, the evidence was grouped and the data labelled as they related to broader perspectives and dimensions (Creswell \& Plano Clark, 2007, p. 131).

The limitations to this study include the relatively small numbers of research participants, rendering generalisability to the broader residential care population problematic. Furthermore, the relationship between the professionals involved in the child's life - keyworker, field social worker and after-care worker-were not addressed in this pilot study and will be included for consideration as the project rolls out.

\section{Findings of the Pilot Study}

This section reports on the findings of this pilot study with reference to the stated aims.

\section{What Keyworking Involves?}

The data collected for this pilot study indicate that keyworking in residential care in Ireland retains its original features as described by Mallinson (1995) and continues to exhibit role functions that involve day-to-day responsibility for the identification and responses to the needs of the young person at the centre of the keyworking relationship. The data contain much information on the practical issues attended to by keyworkers, including making contact with family of origin and outside services, liaising with the young person's school, keeping records related to the general wellbeing and experiences of the young person, providing them with information about a wide variety of topics and making sure their basic needs are met. Furthermore, there was ample evidence from the data that keyworkers acknowledge a role for keyworking beyond simply meeting the practical needs of the young people in care, but one that extends to addressing and attempting to meet the relationship needs of the young people in their charge. Keyworkers described their focused attention to building relationships with young people in care, working with young people in the context of 
those relationships and using the strength of the relational bond as a basis for helping the young person prepare for and negotiate the transition into after-care and postcare independence.

\section{What Keyworking Means to the Key Stakeholders}

Across the range of service providers interviewed in the pilot phase of this study was a consistent understanding and acknowledgement of the importance for young people in residential care, to form constructive and supportive relationships with their caregivers. Participants viewed keyworking as a positive method of facilitating the establishment and continuation of supportive relationships. Generally, as reflected in the following quote, the participants explained keyworking as a feature of a wider relationship-based approach operating in their work setting:

Key working is based on a relationship based approach. I believe everyone working here has to have a relationship with the young people, though it can be difficult at times. (Keyworker 1)

Consistently, the participating care providers highlighted the importance of generating a nurturing environment that helped young people develop roots or a sense of belonging to the residential setting. Even for those who worked in short-term and crisis intervention services there was an acknowledgement of the importance of continuity across the young person's life. Keyworking was viewed as a useful method of providing continuity (even when placement moves occurred) and a sense of belonging for the young person, as captured in this quote:

We are his family, his memories, the past, his identity, his support, unconditionally, this is his home. (Keyworker 2)

The narrative of the young person referred to in the above quote, who also participated in this study, similarly reflected a potent bond with his residential unit, resonating with the significance of "secure base" and "felt security" referred to earlier. This next quote illustrates these themes:

This is my home, this will always be my home. They are my family life 'cos they are always here if they say they are going to be. (Care-leaver 1)

In addition, many statements from both participating young care-leavers and care providers indicated that young people in care can easily identify both congruence and indeed incongruence in the relationships they have with their care providers. The following quote captures one young person's recollections of the array of relationships he experienced with caregivers and his ability to distinguish between caregivers who attempted to build meaningful relationships from those who were not so inclined:

Most of the key workers I had I got on with, it depends on the person, but you know automatically the ones that are just coming here to work, that don't really care about you - the ones who just come in here to get paid - and the ones who do [care], you can see it in the work they put into you; they care about the outcome of the work they do with you; [they] don't bullshit you. You know, like doing your 
family life story work - like we went out to where I grew up, that's the good part of doing all that, going back to your roots. Some people will say it is too hard for them, but you have to do it. (Care-leaver 1)

Data from this study support Gaskell's (2009) taxonomy of relationship characteristics that serve to inhibit the formation or quality of positive relationships between young people in care and their caregivers. Participating young people reported difficulty trusting care staff for a number of reasons, including previous abusive relationships in their earlier lives; staff turnover; lack of consultation regarding change of keyworker; and multiple placement disruptions experienced over a relatively short time period, which set them on a trajectory of repeated short-term placements in a variety of settings. In addition to Gaskell's (2009) findings and also echoing Mallinson and Citarella's (1990) point, this present study has identified gender as an additional factor that most of the participating young people raised as an issue that they found inhibited the formation of relationships with their keyworkers at different times during their residential care career. Both male and female young care-leavers reported incidences of being assigned keyworkers of the opposite gender to their own and, for a variety of reasons, finding this a difficult experience. For example, some reported that they felt they had not been included in the decision about who would be their keyworker. Others recalled experiencing significant discomfort with a keyworker of the opposite sex because they were at the age of puberty and reported finding it very difficult to ask questions about the physical and emotional changes they were experiencing. The female care-leavers reported additional embarrassment in asking a male keyworker for help with obtaining personal hygiene items. However, males in the study also reported problems with asking female staff about bodily changes to the point that one young man recalled working up the courage to approach the only adult male he regularly had contact with about why his body was changing. This person was his school teacher, as in his residential unit at the time all of the staff (and all the other residents) were female.

A smaller number of those interviewed alluded to histories of abusive relationships in their early childhood that compromised their ability to establish keyworking relationships with members of the opposite sex. The young people we interviewed, when asked how the issue of gender or any other problematic factors could be addressed when assigning keyworkers to young people in care, all stated that the missing link had been consultation with them before their keyworker was assigned. If they had been consulted, they asserted that they might have had a better chance of sharing some of their concerns or discomfort before the keyworkers were allocated rather than trying to deal with their discomfort in the aftermath. The following extract from one of the interviews captures both the potential benefits of a successful keyworking relationship with a worker of the same gender as well as the additional distress that results from an unwanted change in the keyworking relationship:

For the first couple of years I had a female keyworker . . . it was great cos I never had the mother figure and then she decided that she just didn't want to do keyworking anymore. And I remember being really upset, really upset, really really really upset 
because then they told me that I was getting a man for a keyworker. I couldn't hack it. It set me a million miles back. (Care-leaver 3)

\section{The Role of the Keyworking Relationship in Supporting the Transition Out of Care}

The relationships described by participants were not confined to the time-frames of the young person's period in residential care but appeared to endure and extend into the after-care context. Many instances were illuminated, throughout the participant interviews, of cases where keywork contact endured well into the postcare period. Also evident was the value placed on after-care contact, not only by the young care-leavers who embraced this ongoing support but also by the keyworkers, who acknowledged their sometimes conflicting feelings around the move of the young person out of their care into an often challenging and at times hostile world, as this worker explains:

Of course you worry, you worry because you care and because you know what they have been through. To some degree you have to let go, to have energy and space for the other kids coming though, but it is great when they come back and are doing ok. (Keyworker 5)

The discussion on the transition to after care resonated largely with the existing research. Similar to young people in the general population who look forward to living independently from their family, young people in care were described as "living for the day" that they were no longer in care, until the reality of independent living struck home:

They think they want it until they get it! (Keyworker 6)

Echoing the literature on "readiness" for independence, one care-leaver recalled leaving his residential unit once he reached 18 years of age and was no longer formally in the care of the state, even though he was preparing for his final school examinations:

I wanted to go, I was ready. Like I could have stayed here until I was finished School but I chose to leave when I was in $6^{\text {th }}$ year, so when I was 18 , in $6^{\text {th }}$ year, I was living by myself and I loved it. It was perfect. I loved living by myself and the time was right and it just worked out. They told me I could stay here till I finished [school] and that was sound. (Care-leaver 1)

The importance of preparing for leaving care and independent living is further commented on by this young care-leaver, who explained the significance of his keyworker in this regard:

From about 16 keyworking was great 'cos it was all about getting ready for leaving. A few months before I went they gave me the key of the door and the alarm code. That meant a lot, the trust, it was like a normal family... well almost. (Care-leaver 1)

The capacity of the residential care setting to act as a potential buffer against the post-care vulnerabilities such as loneliness, stress and poverty was also clearly reported on in this study. Care-leavers described regular Saturday or Sunday visits for the evening meal with more infrequent visits to the residential unit for assistance with 
job applications, telephone use and emergency food supplies. While many of the participating young people were linked in with after-care programmes, these connections reflected their current practical and informational needs. Conversely, and of particular significance, the link with the residential unit and the residential keywork staff was described by both participating staff and young people as providing the young people with a safety net, a secure base they could always return to, and a vital sense of continuity between their past, the present and their future. It was also the place the care-leaver described as coming home to, to share their celebrations, their milestones and their special events.

Finally, the importance of the connection to the residential home and the significance of the tie to both people and place is poignantly reflected on and articulated by this participating care-leaver:

Like "leaving care", what does that mean? You don't say "leaving home", you just say moving out. I've moved out of here and I know I am not in care now, but I haven't left here. (Care-leaver 1)

Furthermore, and as referred to earlier, it emerged clearly from the data that the current lack of regulation and legislative footing for after-care services in Ireland meant that residential keyworkers could not always rely on support for this significant role. This support was lacking on a number of fronts, particularly financial support for the continued involvement of the keyworker in the young person's transition to after care, and perhaps more importantly in the form of professional support, in the absence of professional support, supervision and guidance for this role:

There are people who can manage to have relationships with young people in a very appropriate professional way after they have left a service, I am not doubting that but there are others who can't. (After-care worker 1)

But here we have no funding for after care. We either do it on our own time or, like if we do anything outside of here, we are borrowing time for it, or even a dinner, we have to buy it because we have no funding. You do it because sometimes a kid will need it. (Keyworker 7)

The difficulties in mediating between developing genuine concern and deep-level relationships, while at the same time maintaining appropriate boundaries between the staff member and the young person, were articulated quite succinctly in a statement by one of the participating after-care workers:

I have seen keyworking very inappropriately used where people were way too involved and almost the child, the young person becomes another part of them within the work context. Then the young person is getting very mixed messages. I mean, these young people are in care for a particular reason, they need adults around them who are giving them very clear distinct messages and if we start blurring those lines, I think we are just colluding into that world that they have already just left. (After-care Worker 1)

This worker's point touched also on the need to model appropriate levels of involvement in another person's life, something that many young people who enter 
residential care environments struggle to understand because of earlier trauma and sometimes abuse in their lives.

In conclusion, the emerging findings propose that relationships are not only integral to keyworking but are also inextricably linked to successful transitions. As such, keyworking not only has the potential to build relational capacity but also the opportunity to do so, an opportunity perhaps heretofore unavailable to many young people needing alternative care. Critical to achieving optimum keyworking relationships, however, is both clarity about the keyworker role, the process of matching keyworker to young people, which includes consultation with the young people themselves, and the supervision and training of keyworkers as a vital support for staff.

\section{Discussion}

McConnell Gladstone, Boydell and McKeever (2006, p. 2542) remind us that "being identified as 'at risk' is a powerful label" that can follow children into adulthood. With reference to work by Luthar and Cicchetti (2000), McConnell Gladstone, Boydell and McKeever (2006, p. 2543) suggest that resilience in children is not predetermined by their genes but is "substantially shaped by life circumstances". The care staff that vulnerable young people encounter in their care careers have both the opportunity and the capacity to positively influence and "substantially shape" outcomes for the young people in their charge. Focusing on the potential power of the keywork role, two inter-related themes have emerged with significance from the preliminary findings. These concern the concepts of "supportive alliances" with young people and "focused commitment" on the part of the caregivers.

Focusing firstly on "supportive alliances", this research highlighted that keyworking is recognised widely within residential care as a consistently useful medium through which young people can build deep and positive relationships with carers as well as receive a sustained focus on their individual needs. Young people living in residential care are faced with many challenges living within a cared-for environment (Byrne \& McHugh, 2005, p. 318) and also as they move to after-care and eventual independent living (Doolan, 2005; Stein, 2008). Supportive alliances are essentially relationships in which the keyworker adopts an active (as opposed to passive or observer) role in supporting the young person deal with the many issues and difficulties they may experience over the course of their career in residential care. The established empirical knowledge base highlights both compromised relational histories for young people in care (Dunn, 1993; Gaskell, 2009; Howe, 1997; Stein, 2008) and the critical role that relational capacity plays in successful transitions for young people leaving care (Dumaret et al., 2011). It is significant that emerging with clarity from this present pilot study is the endorsement by both young people and carers of the keywork model, which they collectively found broadly useful, positive and negotiable. It was also the primary channel through which their many and often complex needs were addressed and met.

Moving on to the second concept highlighted above, the development of these critical relationships demands a focused commitment on the part of the residential 
keywork staff. Such focused commitment requires the keyworker to engage with the individual needs of the looked-after young person in a way that conveys to the young person that they are committed to working towards getting those needs addressed. One of the key messages emerging from Martin and Jackson's (2002, p. 128) research on educational success for children in state care identifies the critical importance for young people of having a special relationship with a committed carer, something they suggest was akin to a "guardian angel". Similarly, de Boer and Coady (2007) explore the "personal connections" some workers are able to build with service users that help those workers sustain a commitment to the relationship or "going the extra mile". They conclude that such special relationships are not built mechanically but are created through meaningful engagement.

This research indicates that while the keywork role can provide a medium for relationship-based approaches in residential childcare, a clear paradox nonetheless appears to exist regarding the lack of recognition keyworking receives as a central support for the young person when they leave care. This pilot study therefore illustrates both the benefits of flexibly employing keyworking across the divide of incare and after-care in a more "through-care" approach, as Dixon and Stein (2005) advocated, while simultaneously highlighting the rigid borders between "in care" and after care that mitigate against the free-flow of successful keywork relationships. Specifically, this study found that the point at which the young person officially left care also became the point at which the keywork relationship was deemed to officially end, paradoxically at a time when this relationship is most needed. It would seem that having engaged the young person successfully and therapeutically in the "relationship dance" (Stern, 1977), the rhythm and flow of that dance, which developed from the continuity and stability of the keywork relationship (Dixon \& Stein, 2005), is brought to an abrupt finale before either partner in the dance is ready. Despite the lack of official recognition of its endurance, this present study demonstrates, however, that keyworking relationships continue to be a critical yet unofficial source of support for the young person negotiating independent living, often without recognition and at the behest of good will and professional best practice. This paper would argue that this is a positive contribution to helping young people achieve post-care independence and one that deserves recognition as such.

\section{Conclusion}

The research on which this paper is based aims to move knowledge about keyworking from the position where it is an accepted yet unquestioned and uncontested practice to a place where we can engage with keyworking as it currently operates in terms of its positive and negative aspects. This paper argues that it is only by turning the spotlight on keyworking as it is carried out by care-workers and experienced by young people in care or in transition out of care that we will unlock its potential and constructively address any pitfalls that can accompany it. This pilot study has gathered information from both service providers and service users, and now we have in their own words the opinions and experiences of those involved in keyworking to 
help us understand and interpret both what is best and what could be better within keyworking relationships. At this preliminary stage, the data gathered so far support a positive appraisal of keyworking relationships particularly for young people but also raise some critical aspects of this taken-for-granted model of practice, particularly in relation to the hidden and under-resourced keyworking that continues invisibly in some instances where young people have "officially" graduated from care but continue to benefit from ongoing contact with their "former" caregivers/keyworkers. The next stage of the research project will seek to fully explore all of these issues in greater depth with a view to creating a better informed context within which the model of keyworking can be utilised.

\section{References}

Andersson, G. (2005). Family relations, adjustment and well-being in a longitudinal study of children in care. Child and Family Social Work, 10, 43-56.

A Vision for Change. (2006). A vision for change. Report of the Expert Group on Mental Health Policy. Dublin: Stationery Office.

Biehal, N., \& Wade, J. (1996). Looking back, looking forward: Care leavers, families and change. Children and Youth Services Review, 18(4/5), 425-445.

Bilson, A., Price, J., \& Stanley, N. (2010). Developing employment opportunities for care leavers. Children \& Society, 25(5), 382-393.

Byrne, J., \& McHugh, J. (2005). Residential childcare. In P. Share \& N. McElwee (Eds.), Applied social care: An introduction for Irish students (pp. 313-320). Dublin: Gill and Macmillan.

Cashmore, J., \& Paxman, M. (2006). Predicting after-care outcomes: The importance of "felt" security. Child and Family Social Work, 11, 232-241.

Clarke, M. (1998). Lives in care: Issues for policy and practice in Irish children's homes. Dublin: Mercy Congregation/ Children's Research Centre, Trinity College Dublin.

Creswell, J. W., \& Plano Clark, V. L. (2007). Designing and conduction mixed methods research. Thousand Oaks CA: Sage.

Dant, T., \& Gearing, B. (1990). Keyworkers for elderly people in the community: Case managers and care co-ordinators. Journal of Social Policy, 19(3), 331-360.

de Boer, C., \& Coady, N. (2007). Good helping relationships in child welfare: Learning from stories of success. Child and Family Social Work, 12, 32-42.

Department of the Environment, Heritage and Local Government. (2001). The homeless strategy national implementation plan. Dublin: Stationery Office.

Dinisman, T., \& Zeira, A. (2011). The contribution of individual, social support and institutional characteristics to perceived readiness to leave care in Israel: An Ecological perspective. British Journal of Social Work, 41(8), 1419-1423.

Dixon, J. (2008). Young people leaving care: Health, well-being and outcomes. Child and Family Social Work, 13, 207-217.

Dixon, J., \& Stein, M. (2005). Leaving care: Throughcare and aftercare in Scotland. London: Jessica Kingsley.

Doolan, R. (2005). Aftercare. In P. Share \& N. McElwee (Eds.), Applied social care: An introduction for Irish students (pp. 210-224). Dublin: Gill and Macmillan

Dumaret, A.-C., Donati, P., \& Crost, M. (2011). After a long-term placement: Investigating educational achievement, behaviour, and transition to independent living. Child Care \& Society, 25, 215-227.

Dunn, J. (1993). Young children's close relationships: Beyond attachment. Newbury Park, CA: Sage Publications. 
EPIC. (2011). Aftercare - Briefing Document. Dublin: EPIC. Accessed on 14th August 2012 at http:// www.epiconline.ie/aftercare---briefing-document.html

Forkby, T., \& Höjer, S. (2011). Navigations between regulations and gut instinct: The unveiling of collective memory in decision-making processes where teenagers are placed in residential care. Child and Family Social Work, 16, 159-168.

Gaskell, C. (2009). "If the social worker had called at least it would show they cared". Young care leavers' perspectives on the importance of care. Children \& Society, 24, 136-147.

Gilligan, R. (2000). The key role of social workers in promoting the well-being of children in state care - A neglected dimension of reforming policies. Children \& Society, 14(4), 267-276.

Gilligan, R. (2008). Ireland. In M. Stein \& E.R. Munro (Eds.), Young People's Transitions from Care to Adulthood: International Research and Practice (pp. 90-101). London: Jessica Kingsley.

Government of Ireland. (2009) Commission to inquire into child abuse. Dublin: Stationery Office. Retrieved from www.childabusecommission.ie

Government Publications. (1970). Reformatory and industrial schools systems report. Dublin: Stationery Office.

Government Publications. (1980). Task force on child care services - Final report. Dublin: Stationery Office.

Health Service Executive. (2006). LAC 4 U. Leaving and aftercare for you (Leaflet). Dublin: Health Service Executive.

Health Service Executive. (2010). Policies \& procedures for children's residential centres. HSE Dublin North East. Dublin: Health Service Executive.

Hicks, L. (2008). The role of manager in children's homes: The process of managing and leading a well-functioning staff team. Child and Family Social Work, 13, 241-251.

Hicks, L., Gibbs, I., Weatherly, H., \& Byford, S. (2009). Management, leadership and resources in children's homes: What influences outcomes in residential child-care settings? British Journal of Social Work, 39, 828-845.

Holland, S., Faulkner, A., \& Perez-del-Aguila, R. (2005). Promoting stability and continuity of care for looked after children: A survey and critical review. Child and Family Social Work, 10, 29-41.

Houston, S. (2010). Building resilience in a children's home: Results from an action research project. Child \& Family Social Work, 15, 357-368.

Houston, S. (2011). Using action research to enhance resilience in a children's home: An exploration of need, experience and role. Child Care in Practice, 17(2), 115-129.

Howe, D. (1997). Psychosocial and relationship-based theories for child and family social work: Political philosophy, psychology and welfare practice. Child and Family Social Work, 2, 161-169.

Jackson, S., \& Thomas, N. (2001). On the move again? What works in creating stability for looked after children. Ilford: Barnardos.

Kelleher, P., Kelleher, C., \& Corbett, M. (2000). Left out on their own-Young people leaving care in Ireland. Dublin: Oak Tree Press.

Kendrick, A. (Ed.). (2008). Residential child care: Prospects \& challenges. London: Jessica Kingsley Publishers.

Kroll, B. (2010). Only connect... building relationships with hard-to-reach people: Establishing rapport with drug-misusing parents and their children. In G. Ruch, D. Turney, \& A. Ward (Eds.), Relationship-based social work: Getting to the heart of practice (pp. 69-84). London: Jessica Kingsley.

Krueger, R. A. (1994). Focus groups: A practical guide for applied research. Thousand Oaks, CA: Sage Publications.

Krueger, R. A., \& Casey, M. A. (2009). Focus groups: A practical approach for applied research (3rd ed.). London: Sage Publications.

Luthar, S. S., \& Cicchetti, D. (2000). The construct of resilience: Implications for interventions and social policies. Development and Psychopathology, 12, 857-885. 
Mallinson, I. (1992). Social care papers for practice: Keyworking in social care, an interim research report. Coventry: SCA Education.

Mallinson, I. (1995). Keyworking: An examination of a method of individualising care for older people in residential units. Aldershot, UK: Avebury.

Mallinson, I., \& Citarella, V. (1990, April 26). Making the perfect match. Community Care, pp. 27-29.

Martin, P. Y., \& Jackson, S. (2002). Educational success for children in public care: Advice from a group of high achievers. Child and Family Social Work, 7, 121-130.

Mattison, V., \& Pistrang, N. (2000). Saying goodbye: When keyworker relationships end. London: Free Association Books.

McAuley, C., \& Davis, T. (2009). Emotional well-being and mental health of looked after children in England. Child \& Family Social Work, 14, 147-155.

McCann, J., James, A., Wilson, S., \& Dunn, G. (1996). Prevalence of psychiatric disorders in young people in the care system. British Medical Journal, 313, 1529-1530.

McClung, M., \& Gayle, V. (2010). Exploring the care effects of multiple factors on the educational achievement of children looked after at home and away from home: An investigation of two Scottish local authorities. Child \& Family Social Work, 15, 409-431.

McConnell Gladstone, B., Boydell, K. M., \& McKeever, P. (2006). Recasting research into children's experiences of parental mental illness: Beyond risk and resilience. Social Science \& Medicine, $62,2540-2550$.

McCrystal, P., \& McAlooney, K. (2010). Assessing the mental health needs of young people living in state care using the strengths and difficulties questionnaire. Child Care in Practice, 16(3), 215-226.

McLeod, A. (2010). "A friend and an equal": Do young people in care seek the impossible from their social workers? British Journal of Social Work, 40, 772-788.

McNicholas, F., O'Connor, N., Bandyopadhyay, G., Doyle, P., O’Donovan, A., \& Belton, M. (2011). Looked after children in Dublin and their mental health needs. Irish Medical Journal, 104(4), $105-108$.

Mendes, P. (2009). Globalization, the welfare state and young people leaving state out-of-home care. Asian Social Work \& Policy Review, 3, 85-94.

Morgan, D. (1997). Focus groups as qualitative research (2nd ed.). London: Sage Publications.

Mount, J., Lister, A., \& Bennun, I. (2004). Identifying the mental health needs of looked after young people. Clinical Child Psychology and Psychiatry, 9, 363-382.

Mullins, B. (2008). Exploring key working: Parents' perceptions of key workers in Clare Early Intervention Services (CEIS) (Master's thesis in Health Science, National University of Galway, Ireland).

O'Leary, Z. (2005). Researching real-world problems: A guide to methods of inquiry. London: Sage Publications.

Owusu-Bempah, K. (2010). The wellbeing of children in care: A new approach for improving developmental outcomes. London: Routledge.

Pinkerton, J. (2000). Leaving care and fostering. In G. Kelly \& R. Gilligan (Eds.), Issues in foster care: Policy, practice and research (pp. 85-106). London: Jessica Kingsley Publishers.

Residential Care Association/British Association of Social Workers. (1976, September 2). How can residential and field social workers co-operate? Social Work Today, pp. 346-348.

Robson, C. (2002). Real world research (2nd ed.). Oxford: Blackwell Publishers.

Robson, C. (1998). Real world research: A resource for social scientists and practitioner-researchers. Oxford: Blackwell Publishers.

SCA Education. (1991). Keyworking in social care, an introductory guide. Arbiton: Social Care Association.

Sloper, P., Greco, V., Beecham, J., \& Webb, R. (2006). Key worker services for disabled children: What characteristics of services lead to better outcomes for children and families? Child: Care, Health \& Development, 32(2), 147-157. 
Stein, M. (2002). Leaving Care. In D. McNeish, T. Newman, \& H. Roberts (Eds.), What works for children (pp. 59-82). Milton Keynes: Open University Press.

Stein, M. (2008). Transitions from care to adulthood: Messages from research for policy and practice. In M. Stein \& E. Munro (Eds.), Young people's transitions from care to adulthood: International research and practice (pp. 289-306). London: Jessica Kingsley Publishers.

Stein, M., \& Munro, E. (Eds.). (2008). Young people's transitions from care to adulthood: International research and practice. London: Jessica Kingsley Publishers.

Stern, D. (1977). The first relationship: Mother and infant. Cambridge, MA: Harvard University Press.

Thoburn, J. (2008). Social work with children and families. In M. Davies (Ed.), The Blackwell companion to social work (3rd ed., pp. 207-221). Oxford: Blackwell Publishing.

Utting, W., Baines, C., Stuart, M., Rowland, J., \& Vialva, R. (1997). People like us: The report of the review of the safeguards for children living away from home. London: Her Majesty's Stationery Office.

Vinnerljung, B., \& Sallnäs, M. (2008). Into adulthood: A follow-up study of 718 young people who were placed in out-of-home care during their teens. Child and Family Social Work, 13, $144-155$.

Widmer, T., Hirschi, C., Serdult, U., \& Vogeli, C. (2008). Analysis with APES, the Actor Process Event Scheme. In M. M. Bergman (Ed.), Advances in mixed methods research (pp. 150-171). London: Sage Publications. 